\title{
Brazilian urban porosity: treat or threat?
}

1 Igor Moreno Pessoa BA, MA

PhD Candidate, TU Delft, OTB - Research for the Built Environment, Faculty of Architecture and the Built Environment, Delft, The Netherlands

2 Tuna Tasan-Kok BA, MSc, PhD

Assist. Professor, TU Delft, OTB - Research for the Built Environment, Faculty of Architecture and the Built Environment, Delft, The Netherlands
3 Willem Korthals Altes PhD

Professor, TU Delft, OTB - Research for the Built Environment, Faculty of Architecture and the Built Environment, Delft, The Netherlands
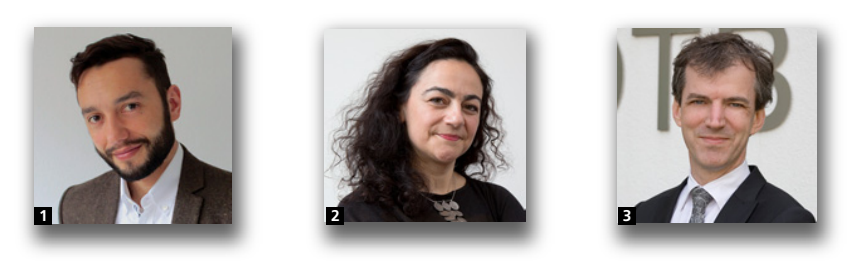

Urban areas have spatial discontinuities, such as disconnected neighbourhoods, brownfield areas and leftover places. They can be captured by the metaphor of urban porosity. This paper aims to highlight the potential social consequences of urban porosity by creating a 'porosity index'. The authors argue that these areas can provide capacity for flexibility, fluidity and absorption in major cities, but that they can also be a source of fragmentation, disconnection and isolation between different social groups, eroding the adaptive capacity of metropolitan systems. Porosity may thus have both positive and negative influences on the resilience of urban systems. Brazil's rapid process of urbanisation over the last $\mathbf{5 0}$ years shows both these sides of porosity, which create treats and threats for its urban systems. This paper develops an analytical framework within which to study how porosity manifests itself in Brazilian metropolises, which helps to identify porosity in the context of urban growth and decline. It uses statistical data from Brazilian Institute of Geography and Statistics relating to 12 Brazilian metropolises to generate the proposed porosity index. Additionally, the paper discusses the added value of the concept of urban porosity in addressing urban resilience and briefly elucidates the issues and opportunities caused by discontinuities in the urban fabric in Brazil's metropolises.

\section{Introduction}

Brazil's urbanisation rate jumped from $44 \cdot 6 \%$ in 1960 to $84 \cdot 5 \%$ in 2010 (Brazilian Institute of Geography and Statistics (IBGE, 2015a)), an increase that was accompanied by an absolute population increase of $270 \%$ (IBGE, 2015b). This rapid process of urbanisation has brought about a fundamental change in Brazilian metropolitan systems. Planning authorities have been challenged beyond their ability to cope with the speed of urbanisation. Major cities' master plans have repeatedly failed to guide the process. These changes have caused a severe shock to the metropolitan environment that cannot be solved by existing planning practices. As a result of accelerating urbanisation and urban growth, and increasing opportunity-driven urban development, a 'patchwork' pattern of development has emerged: different areas have developed, without necessarily being connected to each other, leaving many 'in-between' zones in the urban spatial structure - a phenomenon that the authors call 'porosity'.

Porosity can serve as a metaphor to describe these threshold areas in a discontinuous metropolitan context, and it is particularly common in Latin American cities. In material science, porosity can provide flexibility, fluidity and absorption capacity, but at the same time it can also promote fragmentation, disconnection and isolation. The metaphor of porosity helps us to address a phenomenon of which, despite its increasing prominence and influence in Latin American urban areas, has not yet been the subject of significant scholarly reflection. Within this framework, and using empirical sources, the authors aim to evaluate how porosity may be a source of 
positive and negative effects (or as they call them, treats and threats) on the resilience of urban systems. Porosity can have both a social and a spatial impact. The 'leftover' spaces can provide space for flexibility, fluidity and absorption capacity in large cities, enhancing spatial and social connections in the built environment. On the other hand, they can also contribute to fragmentation, disconnection and isolation between different land-use areas and different social groups, eroding the adaptive capacity of metropolitan urban systems in the case of unexpected changes or disasters. However, the authors also argue that the resilience of a system depends on enhancing the positive dimensions of porosity and minimising its negative dimensions. To do this, the main challenges and opportunities of porosity in a given urban space need to be defined. What is a challenge in one urban system may become an opportunity in a different system. The focus of this study is on Brazil, but it can serve as a basis for further comparative debate with other Latin American countries and even beyond Latin America.

The present paper aims primarily to address how porosity influences Brazilian metropolises, especially the adaptive capacity of urban systems and their resilience. However, it does not aim to elaborate on the reasons for the emergence of the phenomenon of porosity in the first place. A resilient system is better able to absorb shocks and to continue to function, but because porosity is a 'double-edged sword', it is still not clear how porosity may affect resilience overall. Especially in Brazilian metropolises, where there is a high degree of spatial discontinuity in the urban fabric, it is strategically important to understand porosity. How can the positive aspects of porosity be reinforced and the negative aspects minimised? How can a metropolis in Brazil use its porous condition strategically in order to enhance resilience? What opportunities does porosity bring with it? These are some of the concerns addressed in this study. However, the paper's main focus is to understand the extent to which porosity can influence the adaptation of the urban society as a whole to a range of disturbances, even though it is characterised by spatial discontinuity.

Despite the limited scope of this paper, it aims to contribute to the debate on social aspects of urban porosity by creating a 'porosity index' by perceiving urban growth, which is measured in terms of economic, demographic and residential growth, and to urban decline, which is measured in terms of segregation (the incidence of slums or gated communities) and the lack of socio-spatial identification, as the main driving forces of porosity. The authors analyse data from the IBGE gathered from 12 Brazilian metropolises - namely, São Paulo, Rio de Janeiro, Brasília, Manaus, Belém, Fortaleza, Recife, Salvador, Belo Horizonte, Curitiba, Goiânia and Porto Alegre (IBGE, 2008: p. 11). They will first introduce the concept of porosity, in the following section, and then tackle its possible links to resilience in the subsequent section. After defining the challenges posed by Brazilian urban porosity, they will provide an analysis using the statistical data. The paper concludes with a discussion on resilience in porous urban systems.

\section{What is porosity?}

To understand porosity, it is essential to consider the different aspects of porosity and the theoretical debate over the concept. In the past, the metaphor of porosity was not used frequently in urban studies, and on those occasions when it was used, it had no fixed meaning. In other words, the metaphor has been associated with a range of phenomena.

In 1924, the German philosopher Walter Benjamin when writing on Naples, used porosity as a metaphor for the spatial experience of that city. However, the porosity described by Walter Benjamin does not refer to the concept of open or empty spaces, or voids, but rather to the open possibility of encounter, the labyrinthine configuration of space, and the chaotic and unreadable spatial configuration. Furthermore, Benjamin's (1978: p. 170) porosity goes beyond the strict notion of space and also embraces cultural and social aspects.

Porosity results not only from the indolence of the Southern artisan, but also, above all, from the passion for improvisation, which demands that space and opportunity be at any price preserved. Buildings are used as a popular stage. They are all divided into innumerable, simultaneously animated theatres. (...) Porosity is the inexhaustible law of the life of this city, reappearing everywhere. A grain of Sunday is hidden in each weekday, and how much weekday in this Sunday!!!

Hence, Benjamin's concept of porosity goes beyond spatial experience and includes what can be called the 'local Neapolitan lifestyle'. Contemporary authors commonly invoke Benjamin's concept of porosity, which can be seen in the recent work of Paola Viganò (2013: p. 424).

Porosity is a transversal and transcalar concept: ecological (pertaining to the ground, the water problem, of exchange and connectivity), concerning mobility and social issues (democratic accessibility in general), epistemological (the city as a sponge; models of isotropy vs. hierarchy). At the same time it is a precise mathematical concept translated into metaphorical and evocative possibilities for movements.

Viganò's (2013) dissection of porosity into four distinct spheres (ecological, mobility/social, epistemological and mathematical) proposes a clearer identification of the kind of porosity that is being discussed. Within this structure, the porosity addressed in the present paper relates to the social issues caused by spatial discontinuities.

Another approach is to analyse porosity as an aspect of urban morphology. Adolphe (2001) has created a porosity coefficient, 
using the volumes of open spaces and built spaces in a city as variables. This coefficient may play a role in understanding the environmental performance of urban areas, such as the airflow patterns in an urban area.

For Bernardo Secchi (2007), porosity is mainly associated with a phenomenon that he defines as 'the disappearing industrial city' in Europe. This is mainly the consequence of a shrinking population, a rapid increase in the amount of wasteland and structural economic change, whereby old industrial zones which he calls 'outdated infrastructure' - suddenly become empty. This is fundamentally different from Brazilian porosity, since it stems from demographic and economic decline, while in Brazil porosity emerges through just the opposite factors population increase and economic growth. This aspect will be discussed in a subsequent section.

Stavrides (2007), who also refers to Benjamin, uses porosity as a metaphor for the fuzzy boundaries between public and private spaces in Naples. According to Stavrides (2007), this is because porosity promotes the loss of the strict notion of spatial and social order. Porous areas are threshold areas that '... both symbolize and concretize the socially meaningful act of connecting while separating and separating while connecting' (Stavrides, 2007: p. 176). Stavrides (2007) thus also stresses the duality present in the metaphor of porosity, which this paper aims to address.

Keeping these various approaches in mind, the authors' understanding of porosity includes both the social and physical dimensions as they focus on the resilience of metropolitan systems in Brazil and argue that this capacity can be enhanced by porosity zones. Although porosity is usually associated with physically undeveloped or underutilised spaces, the authors' definition of porosity integrates both social and spatial aspects. The concept of porosity in this paper, then, refers not only to underutilised in-between places within densely built-up areas, but also to areas that have the capacity to facilitate the co-existence of places and people due to their location, physical qualities or social infrastructure to accommodate connectivity and self-organisation capacity, as the authors will explain in more depth in the following section. For example, porous areas in cities may provide spaces for the co-production of needs such as food or shelter or spaces for interaction. Thus, they build on the social aspects mentioned by Viganò (2013) and the ideas on the capacity for spatial connectedness mentioned by Stavrides (2007). As stated previously, porosity brings some opportunities with it and the advantages of porosity can be strategically promoted to enhance spatial and social connections in the built environment. As Stavrides (2007: p. 175) affirms, in '... architecture, we usually imagine humans delimiting a territory by marking boundaries. In the rich complexity of city life, however, architecture becomes above all the art of creating passages'. This can be understood as a new method by which to enhance resilience in a complex metropolitan system.

\section{Porosity and urban resilience: a two-sided relationship}

Keeping in mind that porosity refers to spatial fragmentation and discontinuity, the essential question here is whether a porous system can also be resilient. In other words, to what extent do spatial discontinuity and fragmentation influence the urban social system to adapt itself to the new situations created by external effects such as economic, ecological or social crises, and small- or large-scale changes - whether foreseen or unforeseen. If spatial discontinuity leads to social segregation between different groups, to what extent does porosity influence the adaptation of an urban society as a whole to various disturbances?

To start addressing this question, it is important to have a better understanding of resilience. Resilience is 'the capacity of a system to absorb disturbance and reorganise while undergoing change (...) to retain (...) the same function, structure, identity, and feedbacks' (Walker et al., 2004; Wardekker et al., 2010). A resilient system is able to survive, adapt and transform itself (Ludwig et al., 1997), and although it may be changed or influenced by a disaster, it is able to reorganise and reform itself (Tasan-kok et al., 2013). In this sense, porosity can impact on resilience in several ways.

In the literature on resilience, various attributes are defined as the characteristics of resilient urban systems (Eraydin, 2010; Tasan-kok et al., 2013). According to Godschalk (2003), these attributes include redundancy, diversity, efficiency, autonomy, strength, interdependence, adaptability and collaboration. In fact, a resilient city is expected to adapt to uncertainty through the required combination of these attributes (Fleischhauer, 2008; Godschalk, 2003). Walker and Salt (2006) refer to these characteristics as 'qualities' and they also add a social dimension. In their opinion, some of the main qualities include diversity, ecological variability, modularity, acknowledging slow variables, tight feedback, social capital, innovation, overlap in governance and ecosystem services. Since this paper aims to discuss the social impact of porosity, the authors focus on the ideas of social continuity and connection (or in a broader sense, social cohesion), which play an important role in the capacity of the system to cope with uncertainties, since these qualities help communities to communicate easily and organise themselves. Tasan-Kok and Stead (2013) argue that segregated communities have less chance of cooperating and coordinating their action when this is needed. Socio-spatial segregation may also limit the democratic participation of various groups in common action and adversely affect the learning process of adapting to unexpected or expected conditions in the 
development process, which is an extremely important aspect of the capacity for self-organisation and resilience.

Porosity can be linked to fluidity and flexibility, but at the same time to fragmentation and disconnection. As the title suggests, porosity can 'cut both ways' in relation to urban resilience. A highly porous environment can either promote or undermine resilience. This dual relationship will be discussed further in the following sections, but looking specifically at the case of Brazil, it can be argued that spatially discontinuous systems can be socially resilient, if, despite the limited opportunities for interaction between different groups, urban society still manages to cooperate, communicate and organise itself to address the various negative influences involved. In that respect, social resilience approach allows us to keep an open mind about the possible positive aspects of spatial discontinuity when society, despite the limited opportunities for self-organisation, is still able to go on functioning. The next section will address some of the specific characteristics of porosity in Brazilian urban areas, keeping this perspective of resilience in mind.

\section{Urban porosity in the context of growth: the Brazilian case}

Porosity can occur both in situations of decline and in situations of growth. Decline can result in voids in an urban system when functions cease to exist. Bernardo Secchi (2007) has reflected on the structural changes witnessed in many European cities due to shrinking populations and industrial decline. Disused industrial sites in Europe lead to porosity and can also contribute to spatial fragmentation. Secchi (2007) points out how many European cities have responded to this process of decline and looked for answers to the social and economic problems of the 1980 s by filling these urban voids with new functions such as museums, theatres, congress and exhibition halls, office buildings and sport facilities, airports and shopping malls. In that sense, filling urban voids is very closely related to creating new functions for spaces that were previously designated for a different purpose. In other words, the decline of a specific economic activity creates porosity that can be counterbalanced by redeveloping the same space to accommodate new and different functions. This is one of the reasons why in Europe, for example, it is possible to find old church buildings that have been converted into bookshops or nightclubs. These voids in the system also appear in many other older industrial areas such as the American north-east and mid-west, where vacancy is an important issue (Bowman and Pagano, 2004), and in Japan (Dixon et al., 2011).

Alternatively, porosity can also occur in a context of growth, as in Brazil, where growth has occurred in the context of intense opportunity-driven urban development. In that sense, porosity in Brazil is more closely related to the well-known fragmentation of the urban structure of developing countries (Balbo, 1993; Balbo and Navez-Bouchanine, 1995; Coy, 2006; Jaramillo, 1999). There are, then, some major differences compared with the porosity that can occur in a context of decline.

When porosity is a consequence of economic decline, it is naturally viewed as a problem that needs to be resolved. Porosity can be seen as a limit on the space available for investment in the built environment due to its close link with economic development. Porous spaces thus need to be redeveloped, regenerated or given a new function to secure investment. When porosity is the result of growth, as in Brazil, it is not seen as a problem to be resolved, but as a side effect of development, which is viewed in a positive light. The question remains as to whether it is an inevitable side effect of growth or whether porosity can be managed through planning or urban governance in such a way that it can be deemed an independent phenomenon.

Specific to the Brazilian case is the emergence of impenetrable areas, where access is restricted to a specific group. As mentioned by Stavrides (2007), gated neighbourhoods and impenetrable 'favelas' (slums) have an extremely low porosity, in the sense that they are rigid spatial configurations with controlled access and low connectivity with the rest of the city. The status of 'unporous' zone does not, in itself, mean that these zones reduce the porosity of the system as a whole; however, in Brazilian metropolitan areas, slums and gated communities promote extreme spatial fragmentation and disconnection, both of which have an adverse effect on urban porosity. In the specific case of Brazilian porosity, since gated communities and slums are widespread phenomena, they represent a fundamental variable by which to measure the adverse effects of porosity. One of the challenges of analysing porosity in the Brazilian context, then, is to assess the influence of these two phenomena in terms of the effects of spatial discontinuity.

The role of the state in urban development must also be mentioned. In Brazil, the public sector has historically provided limited support for the development of services in the city while claiming to control and produce everything (Balbo, 1993). This historical characteristic is changing in contemporary Brazilian metropolises, since today the state has more resources to devote to urban development and city services. Nevertheless, the previously limited capacity of the public sector influences the way in which porosity is managed today, since public authorities still do not know how to tackle this issue more efficiently or how metropolitan development could prevent the adverse effects of porosity. The lack of any tradition of regulating or managing porosity strategically is, therefore, a challenge. Meanwhile, porosity continues to influence urban economy. 
The influence of urban planning on porosity must also be taken into account. Some argue that porosity in developing countries is mainly the consequence of lack of planning. Nevertheless, this approach is based on a traditional analysis that planning has the power to solve these spatial issues through a top-down approach. Top-down planning, however, has many limitations. The existence of negative aspects of porosity even in highly controlled and planned Brazilian cities, such as Brasília, highlights the limits of planning as a tool. The Brazilian capital, a completely planned city that retains its master plan structure even today, is a notable example of spatial discontinuity and social inequality. Nor, in its suburbs, was the master plan able to create connections between old and new neighbourhoods. In Brazil, then, porosity is not purely the result of lack of planning. Balbo and Navez-Bouchanine (1995), for example, ask whether fragmentation in developing-world cities is an accidental outcome of a lack of planning or is simply how the urban society and economy tends to cope with the constraints of underdevelopment. This perspective adds the notion that in order to confront the difficulties of urban areas in developing countries, a more chaotic but flexible environment may, in fact, be preferable to a planned and rigid approach. Thus, the flexibility provided by porosity may be an opportunity for resilience, although it may also be a source of challenges such as opportunity-led development.

Keeping these challenges and opportunities in mind, it should be emphasised that much of the concept of porosity remains undefined. It is a metaphor and consequently rather imprecise. To study all aspects of porosity, it is essential to wrestle this concept to the ground in a way that will make it possible to operationalise research and measure results in a way that goes beyond figurative expressions.

\section{The Brazilian porosity framework}

To study the level of porosity in Brazilian urban environments and how this relates to growth, a framework was developed based on data from the IBGE's two last national censuses (2000 and 2010). These data allow us to assess the development of some aspects of porosity in Brazilian metropolises. The authors would like to stress, however, that other variables could be added to improve and expand this model, in order to make it more compliant with the metaphor of porosity. For example, IBGE does not measure the number of apartments located within gated communities, it only measures the number of houses. Such data would also be crucial in improving the index, but may also make it more difficult to follow the development of porosity, as no recurrent sources can be found to measure development over time.

The variables have been selected on the basis of the challenges and opportunities highlighted in the previous section. The data used are tailor-made on the basis of what is nationally available. This is consistent with the general tendency in the social sciences that, since many data are nationally based, the scientific measurement of society is also nationally based. Specifically, the authors' analysis of the figures will look at the degree to which Brazilian porosity relates to growth. Additionally, since further studies will be needed to assess how each variable may promote, more or less, urban porosity in relation to other variables, this first version of the porosity index was generated using the same weighting for all variables. Using this strategy, the research aims to produce an index that can serve as a basis for a retrospective comparative analysis of how porosity influences each metropolis. The aim of the research is not to translate the spatial/social concept of porosity into an index in itself. Rather, the porosity index serves more as an analytical tool than as a final product of the research in question. Moreover, the proposed analysis is part of an ongoing research that will address the characteristics of urban fragmentation and spatial discontinuities in the above-mentioned cities in greater depth at a later stage, in order to validate the model.

To analyse porosity, the authors used both input variables (to define growth) and output variables. As input variables, they selected population growth (at the level of the metropolitan municipalities, between 2000 and 2010); economic growth (gross domestic product (GDP) in real terms per head of the population in the metropolitan municipalities) and growth in the number of dwellings (per municipality between 2000 and 2010) (Table 1). This was to provide an insight into the phenomenon of rapid urbanisation. As output variables, the authors selected the share of segregated houses in slums (the IBGE uses the technical term 'subnormal agglomerates') and in gated communities, which is a specific characteristic of porosity in Brazil and is a crucial aspect of porosity. Housing configuration can enhance the negative side of porosity. Moreover, the share of dwellings without a street or number also relates to the social and spatial aspects of porosity mentioned by Walter Benjamin on his visit to Naples in 1924. He refers to the urban labyrinth in which people move around based on less concrete references than a structured numerical system, as in Naples. The high number of dwellings without identification or street names gives a strong signal of how residents interact with their neighbourhood. Even though other aspects of the social perspective of urban porosity could be taken into account, this is fundamental to highlighting the difficulty of having comparable social data that relate to spatial issues from various metropolises. In that sense, the research includes data on dwellings without identification because it was one of the indicators measured using the same criteria in a different metropolitan context in the 2010 Brazilian national census. Moreover, the output porosity index creates an opportunity for further improvement using data from other social dimensions of porosity. 
The output porosity value indicates how much these three variables influence the porosity of each metropolis, enabling comparison and critical analysis. The outcomes (Table 2 and Figure 1) show the distinct position of Belém, scoring highly on porosity due to the occurrence of slums, with over half the city's dwellings considered as part of that category, a number considerably higher than the national average. Furthermore, there is no obvious relationship between growth in the previous 10 years and porosity. Although Manaus and Fortaleza had high growth rates, Belo Horizonte, Curitiba and Goiânia also enjoyed strong growth and rank among the lowest four porosity outputs in the country. This is remarkable because Goiânia, Curitiba and Belo Horizonte are well known for their urban planning. Belo Horizonte and Goiânia are planned cities and Curitiba is often cited as one of the most successful examples of urban planning in Brazil. As mentioned, further investigation is indeed required; however, the authors might speculate that those metropolises perhaps have more proximity with the porosity challenges faced by cities with a well-established planning tradition and do not follow the same patterns of output porosity measured in the index (slums, gated communities, lack of identification). Furthermore, this could also be the case for São Paulo, which used to be the national industrial heartland and, despite several differences, saw its industries move elsewhere in a process similar to that described by Secchi (2007) in European cities.

The porosity index is not directly linked to resilience, but keeping in mind the analytical questions that relate to the challenges and opportunities of porosity, the following section will discuss the relationship between resilience and porosity.

\section{Conclusion and discussion: do spatial discontinuities create opportunities for resilience?}

Metaphorically, porosity can be seen as holes in the urban system that may make a system more brittle and more prone to fragmentation, but may equally be seen as enabling and accommodating new flows and uses in the urban system. Are there opportunities for ensuring that urban porosity can be used for the good? This paper has sought to understand the influence of porosity on the adaptation of urban society as a whole to various disturbances, even when it is affected by spatial discontinuities. On the basis of the above analysis, the authors can conclude that there are several steps to be taken when answering this question.

First, the authors' analysis has shown that each system provides unique porosity conditions in which positive or negative outcomes may occur in terms of resilience, depending on the context. Thus, they can conclude that the local context is crucial in determining how porosity will contribute to the resilience of an urban system. Can one, on the basis of the above 


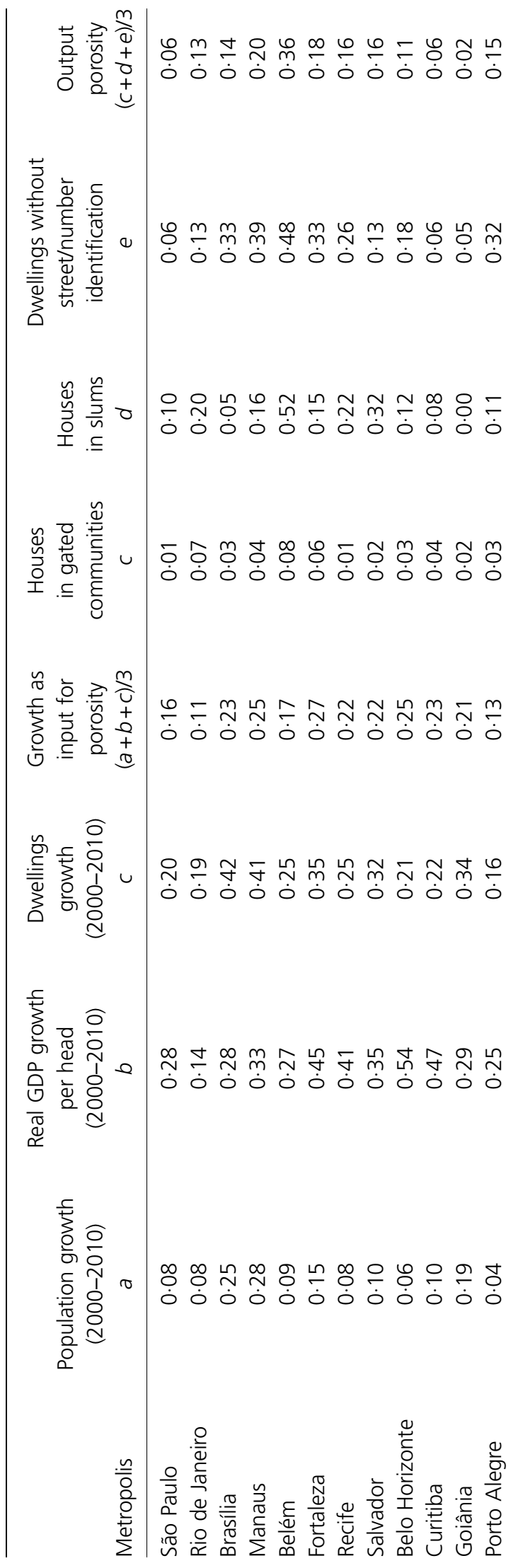

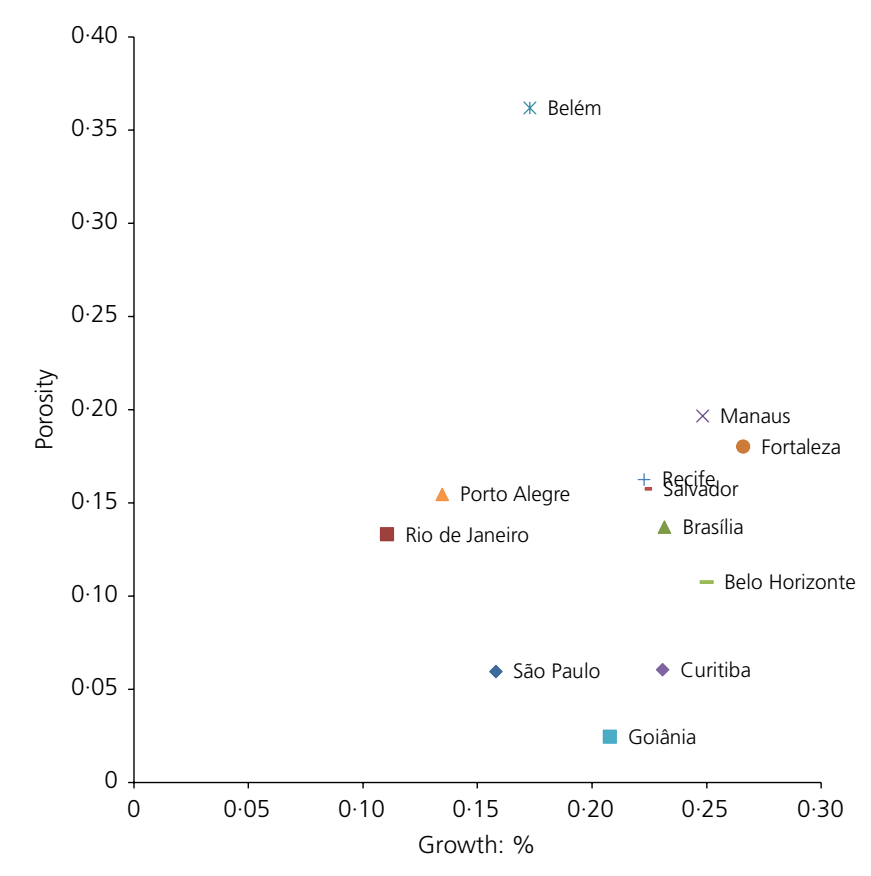

Figure 1. Porosity index of 12 Brazilian cities

analysis, argue that relatively smaller cities such as Porto Alegre and Recife are as resilient as Salvador because they have a similar rate of porosity? Or can one say that Curitiba and Goiânia, both with a lower porosity index, have less opportunity to transform the negative side of porosity into positive aspects and increase their resilience? It is clear that further investigation using local data is required to answer these questions. As mentioned previously, this paper is part of a wider research project that will further investigate the phenomenon of urban porosity, especially spatial fragmentation. This deeper analysis will be fundamental in validating the proposed model and identifying the specifics of each metropolis.

Second, despite its natural limitation and space for further improvement, the porosity index can serve as an analytical tool to assess porosity in a range of contexts to highlight some of the differences between various types of porosity in a distinct metropolitan context. The authors established this index as an initial case in order to test whether they could make a sound analysis for understanding Brazilian metropolises. This index, the variables and the analysis can be developed further by using more data, adding weight to the index, looking for further social aspects, and so on, but the authors' initial result indicates that the porosity index will add to their understanding of the local context of porosity.

Third, the authors can also assert that the link between porosity and resilience can be established through certain policy 
instruments. In other words, this link does not exist naturally, but it can be established by viewing it from a territorial governance perspective. An urban system can also be seen from a territorial perspective focusing on the physical space and the actions that take place on different plots of land, or from a relational perspective that studies the relationships between diverse agents. The authors believe that integrating the relational and territorial approaches can provide opportunities to make use of porosity in urban areas. A specific class of relational/territorial mechanisms are land-based self-organising instruments. These instruments provide the potential for resilience since they can both integrate fragmented spaces and communities, while also allowing them the space for selforganisation, flexibility, cohesion and the potential for change. Examples of these instruments include community land trusts, community benefits agreements, joint development projects, land readjustment, interim use, business improvement districts, industrial improvement districts, urban agriculture regulations and the 'cittaslow' strategy. Zones of porosity may provide the space for such instruments, both in terms of the territorial and policy understanding of the term.

The authors can conclude that porosity provides some treats and some threats at the same time. To enhance the positive aspects of porosity and minimise its negative aspects, it is imperative to identify the main challenges posed by porosity in a specific place. Brasília, for example, has an output porosity of $0 \cdot 14$, very close to Rio de Janeiro at $0 \cdot 13$. Nevertheless, they face very different challenges. Brasília's porosity is not due to the large number of slums and gated communities, which create social and spatial disconnection; however, in Rio this is indeed the main challenge of porosity.

Moreover, porosity has a direct impact on resilience, since fragmented urban environments also tend to be more socially disconnected and to respond less efficiently to economic, social and environmental changes. Porosity can increase or undermine the capacity of a metropolis for resilience, depending on whether it constitutes a treat or a threat. In this sense, when used strategically, porosity represents an exceptional opportunity for improving resilience in the built environment.

\section{Acknowledgements}

The authors are grateful to CAPES foundation for funding Igor Pessoa's research; the OTB Research for the Built Environment and the Brazilian Institute of Geography and Statistics.

\section{REFERENCES}

Adolphe L (2001) A simplified model of urban morphology: application to an analysis of the environmental performance of cities. Environment and Planning B: Planning and Design 28(2): 183-200.
Balbo M (1993) Urban planning and the fragmented city of developing countries. Third World Planning Review 15(1): 23-35.

Balbo M and Navez-Bouchanine F (1995) Urban fragmentation as a research hypothesis: Rabat-Salé case study. Habitat International 19(4): 571-582.

Benjamin W (1978) One-Way Street and Other Writings. Lowe \& Brydine, Thetford, UK.

Bowman AOM and Pagano MA (2004) Terra Incognita: Vacant Land and Urban Strategies. Georgetown University Press, Washington, DC, USA.

Coy M (2006) Gated communities and urban fragmentation in Latin America: the Brazilian experience. GeoJournal 66(1-2): 121-132.

Dixon T, Otsuka N and Abe H (2011) Critical success factors in urban brownfield regeneration: an analysis of 'hardcore' sites in Manchester and Osaka during the economic recession (2009-10). Environment and Planning A 43(4): 961-980.

Eraydin A (2010) Resilient thinking in urban planning and practice. Proceedings of the 24th AESOP, Otaniemi, Finland.

Fleischhauer M (2008) The role of spatial planning in strengthening urban resilience. In Resilience of Cities to Terrorist and Other Threats. Learning From $9 / 11$ and Further Research Issues (Pasman HJ and Kirillov IA (eds)). Springer, Dordrecht, the Netherlands, pp. 273-298.

Godschalk DR (2003) Urban hazard mitigation: creating resilient cities. Natural Hazard Review 4(3): 136-143.

IBGE (Brazilian Institute of Geography and Statistics) (2008) Regiões de Influência das Cidades. IBGE, Rio de Janeiro, Brazil (in Portuguese).

IBGE (2015a) Taxa de Urbanização. IBGE, Rio de Janeiro, Brazil (in Portuguese). See http://seriesestatisticas.ibge.gov. $\mathrm{br} / \mathrm{series}$. asp $\mathrm{no}=10 \& \mathrm{op}=0 \& \mathrm{v}$ codigo $=\mathrm{POP} 122 \& \mathrm{t}=$ taxa urbanizacao (accessed 15/05/2015).

IBGE (2015b) População presente e residente. IBGE, Rio de Janeiro, Brazil (in Portuguese). See http://seriesestatisticas. ibge. gov.br/series.aspx? $n o=10 \& o p=0 \&$ vcodigo $=C D 90 \& \mathrm{t}=$ populacao-presente-residente (accessed 15/05/2015).

Jaramillo S (1999) El papel del mercado del suelo en la configuración de algunos rasgos socioespaciales de las ciudades latinoamericanas. Territorios 2: 107-109 (in Spanish).

Ludwig D, Walker BH and Holling CS (1997) Sustainability, stability, and resilience. Conservation Ecology 1(1). See http://www.ecologyandsociety.org/vol1/iss1/art7/ (accessed 11/06/2015).

Secchi B (2007) Rethinking and redisigning the urban landscape. Places 19(1): 6-11.

Stavrides S (2007) Heteropias and the experience of porous urban space. In Loose Space: Possibility and Diversity in Urban Life (Franck KA and Stevens Q (eds)). Routledge, Abingdon, UK, pp. 174-192. 
Tasan-kok T and Stead D (2013) Analysing the socio-spatial vulnerability to drivers of globalisation in Lisbon, Oporto, Istanbul, Stockholm and Rotterdam. In Resilience Thinking in Urban Planning (Tasan-kok T and Eraydin A (eds)). Springer, Dordrecht, the Netherlands, pp. 71-92.

Tasan-kok T, Stead D and Lu P (2013) Conceptual overview of resilience: history and context. In Resilience Thinking in Urban Planning (Eraydin A and Tasan-kok T (eds)). Springer, Dordrecht, the Netherlands, pp. 39-52.

Viganò $\mathrm{P}$ (2013) Urbanism and ecological rationality. In Resilience in Ecology and Urban Design: Linking Theory and Practice for Sustainable Cities (Pickett STA,
Cadenasso ML and McGrath B (eds)). Springer, Dordrecht, the Netherlands, vol. 3, pp. 407-426.

Walker B and Salt D (2006) Resilience Thinking: Sustaining Ecosystems and People in a Changing World. Island Press, Washington, DC, USA.

Walker B, Holling CS, Carpenter SR and Kinzig AP (2004) Resilience, adaptability and transformability in social-ecological systems. Ecology and Society 9(2). See http://www.ecologyandsociety.org/vol9/iss2/art5/ (accessed 11/06/2015).

Wardekker JA, Jong Ad, Knoop JM and Sluijs JPvd (2010) Operationalising the resilience approach to adapting an urban delta to uncertain climate changes. Technological Forecasting and Social Change 77(7): 978-998.

\section{WHAT DO YOU THINK?}

To discuss this paper, please email up to 500 words to the editor at journals@ice.org.uk. Your contribution will be forwarded to the author(s) for a reply and, if considered appropriate by the editorial panel, will be published as discussion in a future issue of the journal.

Proceedings journals rely entirely on contributions sent in by civil engineering professionals, academics and students. Papers should be 2000-5000 words long (briefing papers should be 1000-2000 words long), with adequate illustrations and references. You can submit your paper online via www.icevirtuallibrary.com/content/journals, where you will also find detailed author guidelines. 